\title{
The Reality of the Application of Intellectual Property Legislation on Digital Information Resources at the Libraries of Public Universities in Jordan (Dissertation)
}

\author{
Afaf Abu Sirhan \\ Library and Information Department, Collage of Arts, Al-Hussein Bin Talal University, Maan, Jordan \\ Email address: \\ octaaas@yahoo.com \\ To cite this article: \\ Afaf Abu Sirhan. The Reality of the Application of Intellectual Property Legislation on Digital Information Resources at the Libraries of \\ Public Universities in Jordan (Dissertation). American Journal of Information Science and Technology. Vol. 5, No. 3, 2021 , pp. $73-79$. \\ doi: 10.11648/j.ajist.20210503.13
}

Received: April 25, 2021; Accepted: May 12, 2021; Published: August 31, 2021

\begin{abstract}
Despite the scientific and technological development, libraries of Jordanian universities suffer from an obvious lack of digital information resources, because for many reasons, the most important of these is the non-application of intellectual property legislation (IPL) related to these resources. This study investigated the reality of the application of intellectual property legislation related to digital information resources at the libraries of public universities in Jordan. The population study consisted of all employees of departments of digital information resources. The study sample was (74) employees. Texts of regulations for the intended libraries and the Jordanian copyright law No. (22) for the year (1992) were reviewed and analyzed. In addition, a questionnaire was developed regarding the actual application of intellectual property legislation relating to digital resources at the university libraries in Jordan. Results revealed that the application of IP legislation relating to digital resources at the libraries of public universities in Jordan was moderate and that the supervising to the libraries of universities from the National Library regarding the protection of intellectual property rights of digital resources was moderate. The study recommended the application of intellectual property legislation related to digital resources in the intended libraries, this could be achieved through including intellectual property legislation in the regulations of public services in the intended libraries, to provide for the terms of protecting IP rights for digital resources, improving the legislation, developing of the Jordanian copyright law to be compatible with digital information resources, providing the necessary support for these libraries, and emphasizing the role of the National Library.
\end{abstract}

Keywords: Intellectual Property Legislations, Public University Libraries, Jordan

\section{Introduction}

Despite the scientific and technological development, libraries of Jordanian universities suffer from an obvious lack of digital information resources, because for many reasons, the most important of these is the non-application of intellectual property legislation (IPL) related to these resources.

Authors, who own the rights of these resources, refuse to make their works available in these libraries because of the fear of infringement on their (physical and moral) rights, because in their view there is no legislation related to the protection of intellectual property rights for digital resources in Jordan, or because libraries do not apply any legislations.
Failure in protecting intellectual property does not encourage creators because of the lack of physical and moral benefits of their scientific and artistic production. The problem of the study is to identify the reality of the application of (IPL) on digital resources in the libraries of public universities in Jordan from of view of their employees.

\section{Objectives and Questions}

This study aims to identify the reality of the application of intellectual property legislation (IPL) on digital resources in libraries of Universities in Jordan by identifying the 
following:

What are the instructions that direct users to preserve intellectual property rights?

To what extent employees of these libraries aware of (IPL) related to digital information resources.

To what extent do the regulations and instructions of libraries contain clauses that recognize preserving the intellectual property rights of digital information resources from the view of their employees?

To what extent do Jordanian libraries apply (IPL) related to the digital information resources from the view of their employees?

To what extent is the controlling and supervising of the National Library of Jordan on the digital information resources from the view of its employees?

\section{Importance of the Study}

This study focuses on the subject of intellectual property legislation related to digital resources. Its importance lies in connecting this subject with the libraries of public universities in Jordan, which is the basic source that provides researchers and scholars from the university community with various resources of information to carry out their scientific research. Protecting the rights of authors and publishers will encourage them to accept the availability of their works in the intended libraries. Thus, the study will benefit the administrations in developing strategies aimed at protecting intellectual property rights related to digital information resources in the intended libraries, as well as enriching published literature with a study on the topic of application of intellectual property legislation for digital resources in libraries, especially since there are few studies dealing with such a topic.

\section{Study Sample}

This study uses the descriptive approach, with a population consisted of all employees working in managing digital information resources in the university libraries. The number of employees was (74).

Data collection tools

For the purpose of this study, the following tools were employed:

1. Reviewing regulations of the intended libraries and analyzing their texts relating to intellectual property rights.

2. Reviewing of the Jordanian Copyright Law No. (22) of 1992 and working on analyzing its texts regarding the intellectual property rights of digital resources.

3. Questionnaires distributed to employees and administrators in the intended libraries.

4. Individual interviews for officials in IP institutions in Jordan, namely the National Library and the Arab Intellectual Property Society.

5. Observations and frequent visits to the sites of the intended libraries.
6. Use of Statistical Package in Social Sciences (SPSS) to analyze the results of the study.

\section{Literature Review}

Rahman, M. H. (2020) [1] aimed to investigate the present practicing situation of digital record management in the university libraries of Bangladesh, and identifying the present preservation scenario, find out the problems which are faced by archivists for long-term preservation, identify the necessary tools and technologies for DRM, and explore the ways to overcome the existing problems. Survey methods were used for gathering data using a well-structured questionnaire. The findings revealed that there are some obstacles to practice DRM, as lack of stable preservation software, the insufficient budget, shortage of digital records, lack of proper training of library professionals, and these also provided some suggestions, such as allocation of the adequate fund, infrastructure development, the simplicity of the intellectual property act, the willingness of authority regarding the implementation of DRM and frequently training for library professionals.

Tomczyk, Ł. [2] (2020) aimed to assess the level of digital literacy (DL) among teachers. The study was diagnostic in order to demonstrate DL in six selected main areas: ergonomics for using ICTs, assessment of information credibility, secure online communication, and maintenance of anonymity in the digital world, secure login, and intellectual property. DL was measured using a knowledge and aptitude test. The study was conducted in Poland in 2017/2018 on 701 teachers. Based on the data collected, we observed the following: Respondents possess the lowest level of knowledge in the field of intellectual property law and know the most about the business environment. Moreover, the Dunning-Kruger effect is noticeable among educators, in the context of the DL assessment associated with digital safety. We also need to emphasize that for educators, digital learning is one of the main safeguards in digital safety, in an overall perspective, in schools.

Trencheva T., Todorova T., Tsvetkova E. [3] (2018) study on copyright literacy for specialists in library and other cultural institutions, conducted in Bulgaria in 2013, highlights serious gaps in knowledge and awareness, and the inability of professionals to deal with copyright issues arising in real business environments. The report presents its own educational intellectual property model for LIS students, implemented in the undergraduate program "Library and Information Management" from AY 2013/2014 to date, as an answer to the entrenched knowledge gap. The University of Library and Information Technology Studies (ULSIT) has contributed to the successful diffusion of knowledge in the field of intellectual property, as there are already 20 years of experience in non-attorneys' intellectual property courses. Despite the recognition of the importance of IP training for LIS students and professionals

Suciu, M. C., \& Fanea-Ivanovici, M. [4] (2018). The main objective of this paper is to discuss how to access digital 
cultural content, as it is found in digital libraries, and special emphasis is placed on the issue of intellectual property rights. The technological and scientific revolution in knowledge, society, and the economy based on innovation has transformed all aspects of life, including those related to cultural content consumption, creativity, and access. Although libraries, archives, and museums will continue to exist and function physically, a trend has been observed to preserve world cultural heritage and provide access to it through digital libraries. Among the European goals included in the Europe 2020 strategy, we find the digitization of cultural content and the development of a library that can store and preserve European culture. The study specifically refers to the state of the European digital library, Europeana. The main scientific research method used in the paper is the critical analysis of intellectual property legal regulations. Thus, we discuss the main implications of these regulations on the digitization process, after which we identify the main current legal opportunities and obstacles in the way of digitizing cultural content.

Kurnilasari, D. T., Yahanan, A., \& Rahim, R. A. [5] (2018) research applies the method of jurisprudential research. The problems that discussed in this article are the type of traditional knowledge documentation system used in Indonesia and how it is implemented in order to protect traditional knowledge. The objectives of this research are to learn about the traditional knowledge documentation system in Indonesia and to compare it with other countries that also use documentation as a method of protection. As a result, the traditional knowledge documentation system used in Indonesia is external registries by parties outside of indigenous communities (government, academics, NGOs) and information related to traditional knowledge is placed in the public domain. It can be summarized that the documentation of traditional knowledge has a vital role to play as one of the most practical methods of performing traditional knowledge protection. In order to protect traditional knowledge, these documented activities need to be strengthened so that they can have a financial benefit for indigenous communities as their owners.

Tella, A., \& Kwanya, T. (Eds.). [6] (2017) explained that Intellectual property is a major challenge for digital libraries. This is because laws, licenses, and technology restrict access to information in digital libraries approved by intellectual property owners. Therefore, the intellectual property makes it difficult for digital libraries to make works discoverable and accessible. Likewise, intellectual property fragments the ownership of copyright, making it difficult for digital libraries to obtain proper consent for content. To meet these challenges, digital libraries are embracing the open access movement that allows digital content to be read, copied, downloaded, and shared as long as creators are cited and recognized. In addition, digital libraries provide access to digital works produced under Creative Commons licenses. These licenses give copyright owners the freedom to modify the copyright of their work to make room for sharing, use, and building on the work.
Niqresh, M. [7] (2019) aimed at identifying the concept of the digital library and related intellectual issues by presenting its definition, development, functions (selection and acquisition of information resources from the web, sources indexing, communication, and management of intellectual property rights, production of electronic resources and its availability, and digital resources maintaining), it also discusses types of Intellectual Property and copyrights, the problems and challenges of a digital library, and its future. The study concluded that digital libraries have emerged because of the mandatory revolution of the third millennium, which is called the communications revolution, as the libraries able to demonstrate their ability to stand up and deal with all the modern technologies, where there is no conflict. Among the new and modern trends in the issue of libraries and the necessity to take the necessary legal procedures with regard to maintain intellectual property rights of authors.

Lor, P. J., \& Britz, J. [8] (2005) investigated current trends in knowledge production and their impact on the international flow of information from an African perspective. Showed that intellectual property is a moral rather than a legal view took off, the authors' concern is that the balance between the public good and private interests has been disturbed, it is premised that there are general moral principles that can serve as a basis for decisions information flows. Three ethical pillars serve as a basis for reflection on current information flows. These are social justice, human rights, and the concept of the common good. Current developments in scholarly publishing and intellectual property rights that affect the North-South information flow are examined, and responses to the growing imbalance between rights holders and authors, such as the open access movement, are considered. These developments also affect South-North information flows, where both exploitation and neglect of Africa's knowledge resources need to be countered.

Taylor, N. G., Jaeger, P. T., McDermott, A. J., Kodama, C. M., \& Bertot, J. C. [9] (2012) aimed at assessing the current situation for copyright law in the United States and the policies for protecting copyrights. The study addresses the current challenges of copyright law, among these challenges, are: the problem of ownership and licensing of digital content in libraries; and the copyright law for digitizing contents in libraries and for the electronic resources available in websites is not clear. It also addresses the Digital Millennium Copyright Act and Fair Use and its terms. The study recommended a greater focus on the definition and clarification of copyright in various ways, and developing effective policies to correct the imbalance between the interests of users and the interests of copyright holders.

Kallinikou, D., Papadopoulos, M., Kaponi, A., \& Strakantouna, V. [10] (2009, April) aimed to address intellectual property issues related to digital libraries in the Internet age. It also aims at clarifying the importance of technology, especially the Internet, in the development of societies and in the preservation and dissemination of culture and knowledge. The study also focuses on some legal issues and considers proposals to protect intellectual property law 
for the open-access of creative works provided to users through digital libraries. The study concluded that legal legislations are important for collecting, digitizing, archiving, and distributing digital resources to ensure continuity of operation and maintenance of digital libraries.

Hoorn, E., \& Van der Graaf, M. [11] (2006) dealt with copyright issues in open access research journals, a survey aimed at presenting the views of authors in the UK and the Netherlands on open access. The aim of this study is to encourage libraries and academic institutions to take account of the views of the authors and not to oppose the interests of these libraries and institutions with their interests in copyright. The study showed three models of copyright in the open-access environment, which not found in traditional journals:

1. The model in which the author keeps copyright: Almost half of the respondents have preferred it.

2. The model in which the author shares the copyright with the publisher (with some common licenses), which was favored by almost one-third of the respondents.

3. The model that transfers only the rights of exploitation to the publisher of the journals; this model was preferred by a small number of respondents (16\%).

The study also found that the majority of authors agreed after approval to access their electronic works in institutions and libraries, but for educational and scientific purposes and not for commercial purposes.

Crews, K. D. [12] (2001) aimed at providing a brief summary of the United States Copyright Act and exceptions provided, with emphasis on its importance for digital music libraries. The study mentions the legal rights of authors according to US legislation, and violations that may occur on these rights by individuals. The study also mentions the Digital Millennium Copyright Act, which added new copyright laws such as the right to prevent circumvention of technological protection systems for digital information resources, and the right to control access to copyrighted digital works. The study also focused on exceptions given to libraries and non- Profitability for the use of digital information resources for scientific research and education.

Prudence Adler [13] (2001) aimed at addressing intellectual property and copyright legislation and the Digital
Millennium Copyright Act (DMCA), which benefits rights holders and includes the following issues: access and fair use of the encrypted works, the responsibility for online service providers to face the violations that occur by users, using of digital technology for user identification, type of use, and related licenses to protect library and archival materials. The study recommends the importance of fair use for balancing the interests of users and rights holders. The study concluded that the Digital Millennium Copyright Act has disadvantages such as the restrictions on libraries, research, and educational institutions in accessing information, which should be excluded from such restrictions, and the importance of reducing restrictions and control of access to information for libraries and research institutions, and the need to provide a new legal framework for addressing digital issues.

Thomas B. Fowler [14] (2001) aimed at clarifying the impact of technology on intellectual property in the Internet age. The study also discusses the Digital Millennium Copyright Act of 1998 and some of its problems related to it. Results show that intellectual property protection is primarily based on legal infrastructure and technological means. It also concluded the importance of developing a legal infrastructure for the protection of intellectual property. In addition, it shows that the problem of intellectual property protection has two aspects: protection against large-scale theft (or companies) and protection against small (or individual) theft, which is considered the most serious piracy. In the past, legal methods have been developed to deal primarily with largescale theft, while technological methods to theft remain individual or small. However, with modern technological developments, especially in the digital and Internet fields, it is difficult to control this problem, especially in institutions and libraries that rely mainly on digital information resources. The study ultimately focused on the importance of digital rights management (DRM) technology to solve the problem of intellectual property protection in this age.

\section{Results}

First, results related to the first question: How well do employees in Libraries of Public Universities know about IP legislation related to digital information resources.

Table 1. Shows the arithmetical averages, standard deviations, degree of knowledge and order of terms related to the knowledge of employees in libraries about intellectual property legislation related to the digital information resources.

\begin{tabular}{|c|c|c|c|c|c|}
\hline Number & statement & Mean & $\begin{array}{l}\text { Standard } \\
\text { deviation }\end{array}$ & $\begin{array}{l}\text { Degree of } \\
\text { knowledge }\end{array}$ & ranking \\
\hline 1 & I have a knowledge about the Jordanian copyright law & 2.97 & 0.877 & Medium & 3 \\
\hline 2 & $\begin{array}{l}\text { There is a clarity in the provisions of the Jordanian Copyright Law concerning the digital } \\
\text { information resources }\end{array}$ & 2.82 & 1.080 & Medium & 2 \\
\hline 3 & I have a knowledge about intellectual property legislation related to digital information & 2.71 & 0.973 & Medium & 1 \\
\hline
\end{tabular}

Second: Results related to the second question: To what extent do the regulations and instructions in Libraries of Public Universities contain items for the protection of intellectual property rights relating to the digital information resources from the view of their employees? 
Table 2. The arithmetical averages, standard deviations, degree of inclusion and order of statements related to the inclusion of items for the protection of intellectual property rights relating to the digital information resources from the view of their employees.

\begin{tabular}{|c|c|c|c|c|c|}
\hline Number & statement & Mean & $\begin{array}{l}\text { Standard } \\
\text { deviation }\end{array}$ & $\begin{array}{l}\text { Degree of } \\
\text { Inclusion }\end{array}$ & ranking \\
\hline 1 & $\begin{array}{l}\text { The library ensures that there are an items for protection intellectual property when offers the } \\
\text { tenders for copying services and within its agreements }\end{array}$ & 3.26 & 1.305 & Medium & 3 \\
\hline 2 & $\begin{array}{l}\text { The library uses adequate guidance for users to demonstrate controls over the copying, } \\
\text { loading or printing digital information resources }\end{array}$ & 3.21 & 1.376 & Medium & 1 \\
\hline 3 & $\begin{array}{l}\text { The Library is keen to demonstrate the protecting of intellectual property rights over the } \\
\text { digital information sources when user is browsing it }\end{array}$ & 3.15 & 1.327 & Medium & 2 \\
\hline 5 & Staff are trained to commit to intellectual property protection for digital information sources & 2.89 & 1.299 & Medium & 4 \\
\hline
\end{tabular}

Thirdly, Results related to the third question: What is the extent of applying the intellectual property legislation for the digital information resources in the in the intended libraries.

Table 3. Shows the arithmetical averages, standard deviations, degree of application and order of statements related to the application of the intellectual property legislation for the digital information resources.

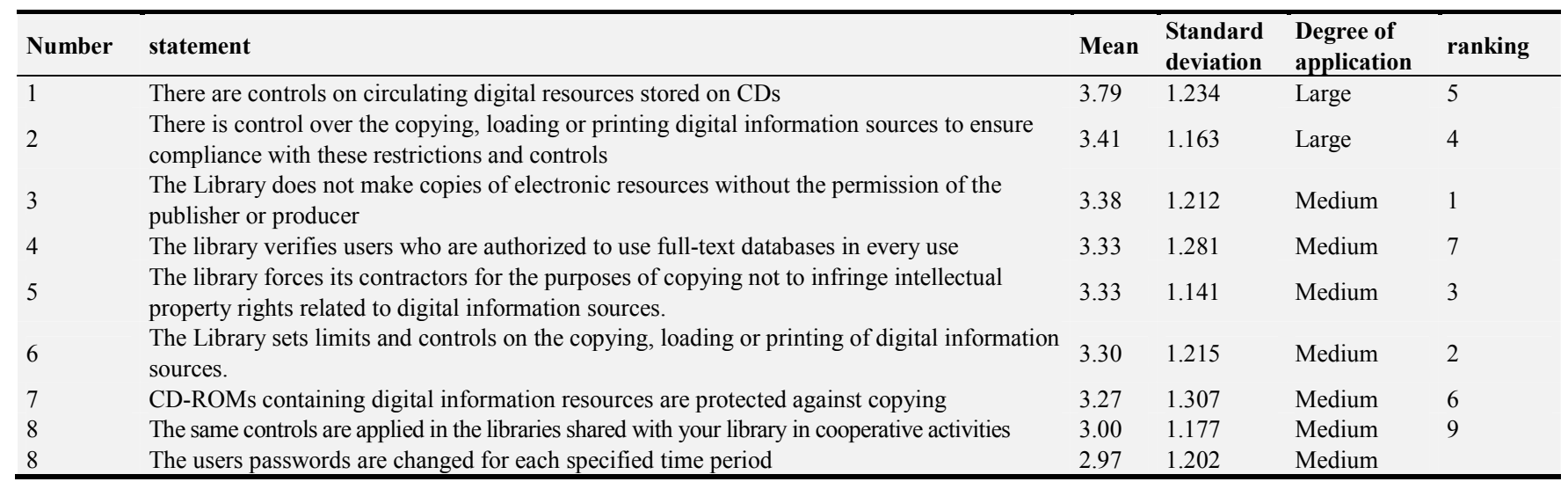

Fourth, Results related to the fourth question: To what extent the supervision and monitoring of the National Library for libraries in universities related to digital information resources from the view of employees.

Table 4. Shows the arithmetical averages, the standard deviations, the degree of supervision and monitoring and the order of words related to the supervision and monitoring of the National Library.

\begin{tabular}{|c|c|c|c|c|c|}
\hline Number & statement & Mean & Standard deviation & Degree & ranking \\
\hline 1 & $\begin{array}{l}\text { The National Library controls the intellectual production of digital information } \\
\text { resources and inform the library about it }\end{array}$ & 3.11 & 1.299 & Medium & 1 \\
\hline 2 & The National Library controls digital information resources and its uses in libraries & 3.05 & 1,143 & Medium & 2 \\
\hline 3 & $\begin{array}{l}\text { The National Library monitors the infringement of intellectual property related to } \\
\text { the digital information resources }\end{array}$ & 2.91 & 1.224 & Medium & 3 \\
\hline
\end{tabular}

\section{Conclusions}

1. After reviewing instructions and regulations of public services directed to users in the Libraries it's found that instructions do not include enough statements mentioning the protection of intellectual property rights to the digital information resources available therein, unclear instructions for use may lead to abuse.

2. The protection of intellectual property rights leads to encourage creativity and creators, which is reflected in the development of scientific research, therefore international and national legislation including the Jordanian Copyright Act No. (22) of 1992 were established to protect these rights.
3. There are many international and local organizations concerned with the protection of intellectual property rights, notably the World Organization of WIPO, and in Jordan the copyright office in the National Library.

4. The digital information resources are literary works protected by the Jordanian Copyright Law No. (22) of 1992, which has been modified to keep pace with recent developments, including digital works.

5. There is a lack of information awareness among employees of libraries in universities regarding intellectual property legislation, and lack of information awareness about IP legislation related to digital information resources or Jordanian copyright law, and there is little clarity for them regarding these laws.

6. Employees are not sufficiently trained to apply 
intellectual property protection related to digital information resources.

7. Jordanian libraries of Universities do not use enough adequate guidance tools for users to show them controls on copying operations or download or print digital information resources, which indicates that there is a weakness in the information awareness among the users to respect intellectual property legislations.

8. Some libraries make some mistakes as they do not apply intellectual property legislation relating to digital information resources significantly, such as making copies of CD-ROMs and electronic information resources, digitizing books without permission of the publisher or producer, not verifying authorized users in each use, not to obligate their contractors for the purpose of copying not to infringe intellectual property rights, not setting limits and controls on the copying, loading or printing of resources digital information, or not setting effective technological methods to protect intellectual property for digital information.

9. National Library monitors libraries with regard to digital information sources and protection from infringement, but not in an efficient way.

\section{Recommendations}

According to the results, there is a set of recommendations, as follow:

1. Balance between author's rights and users need for information in the Jordanian Libraries through the fair use of the digital information resources.

2. Including statements stipulating the protection of intellectual property rights in the public service regulations and instructions in the libraries that directed users of the digital information sources available therein.

3. Establishing regional Arab societies to manage rights of authors in the digital environment, and establishing rules and regulations for these associations.

4. Striving towards improving legislation in the field of protection of intellectual property rights in Jordan and developing the Jordanian copyright law to suit the digital information resources.

5. Promoting culture of intellectual property and awareness of the need for international and national protection of intellectual property through various media, seminars, conferences, research and studies that disseminate and consolidate such a culture and invite civil society organizations to contribute in promotion of intellectual property awareness and culture.

6. Providing financial support to the intended libraries in order to implement their intellectual property laws.

7. Developing training programs that improve the efficiency of Jordanian university libraries in the application of intellectual property legislation related to digital information resources.

8. Developing a systematic framework for teaching intellectual property subjects in the fields of library science in Jordanian universities, to increase awareness of their importance.

9. The imposition of digital protection systems and the extensive use of digital rights management systems in destination libraries.

10.Emphasizing the role of the National Library in protecting the intellectual property of digital information resources by increasing its supervising and monitoring for the intended libraries, and finding ways and mechanisms to verify the non-infringement of copyright for digital resources.

\section{References}

[1] Rahman, M. H. (2020). Review of digital record management needs for academic libraries. Library Hi Tech News.

[2] Tomczyk, Ł. (2020). Skills in the area of digital safety as a key component of digital literacy among teachers. Education and Information Technologies, 25 (1), 471-486.

[3] Trencheva T., Todorova T., Tsvetkova E. (2018). Intellectual Property Training of Library and Information Management Bachelor's Students. In: Kurbanoğlu S., Boustany J., Špiranec S., Grassian E., Mizrachi D., Roy L. (eds) Information Literacy in the Workplace. ECIL 2017. Communications in Computer and Information Science, vol 810. Springer, Cham. https://doi.org/10.1007/978-3-319-74334-9_31

[4] Suciu, M. C., \& Fanea-Ivanovici, M. (2018). The European digital library (Europeana). Concerns related to intellectual property rights. Juridical Tribune Journal= Tribuna Juridica, 8 (1), 244-259.

[5] Kurnilasari, D. T., Yahanan, A., \& Rahim, R. A. (2018). Indonesia's Traditional Knowledge Documentation in Intellectual Property Rights' Perspective. Sriwijaya Law Review, 2 (1), 110-130.

[6] Tella, A., \& Kwanya, T. (Eds.). (2017). Handbook of research on managing intellectual property in digital libraries. IGI Global.

[7] Niqresh, M. (2019). Digital Library and Intellectual Issues-Issues in Copyright and Intellectual Property. International Education Studies, 12 (1), 114-127.

[8] Lor, P. J., \& Britz, J. (2005). Knowledge production from an African perspective: International information flows and intellectual property. The International Information \& Library Review, 37 (2), 61-76.

[9] Taylor, N. G., Jaeger, P. T., McDermott, A. J., Kodama, C. M., \& Bertot, J. C. (2012). Public libraries in the new economy: Twenty-first-century skills, the internet, and community needs. Public Library Quarterly, 31 (3), 191-219.

[10] Kallinikou, D., Papadopoulos, M., Kaponi, A., \& Strakantouna, V. (April 2009). Alternative system for noncommercial use of intellectual property in consideration of free P2P file-sharing. In IASA 2009 Annual Conference, Athens, Greece.

[11] Hoorn, E., \& Van der Graaf, M. (2006). Copyright issues in open access research journals. D-Lib Magazine, 12 (2), 1082-9873. 
[12] Crews, K. D. (2001). The law of fair use and the illusion of fair-use guidelines. Ohio St. LJ, 62, 599.

[13] Prudence Adler (2001). Copyright and Intellectual Property Legislation and Related Activities. Journal of Library Administration; 35:107-118. DOI: $10.1300 / \mathrm{J} 111$, vol 35 no ( $\left.\begin{array}{lll}03 & 09\end{array}\right)$.
[14] Thomas B. Fowler (2001). The Impact of Technology on Intellectual Property Rights. The telecommunications review, pp: $33-64$. 